\title{
POTATO FARMERS PERCEPTION TO DIMENSIONS OF CONTRACT FARMING AND PROSPECTS OF AGRICULTURAL EXTENSION WORK THEREIN IN SOME VILLAGES, BELKAS DISTRICT, DAKAHLIA GOVERNORATE Shalaby, Asmaa $\mathrm{H}$.
}

Agricultural Extension \& Rural Development Research Institute, ARC

$$
\begin{aligned}
& \text { إدراك زراع البطاطس لأبعاد الزراعة التعاقدية ومرتقبات العمل الإرشـادى الزراعى }
\end{aligned}
$$

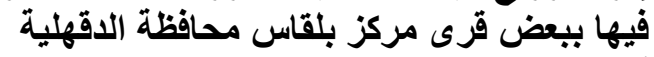

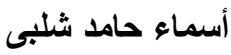

$$
\begin{aligned}
& \text { معهل بحوث الإرشاد الزراعى والتنمية الريفية ـ مركز البحوث الزراعية } \\
& \text { المستخلص }
\end{aligned}
$$

استهدف هذا البحث بصفة رئيسية التعرف على إدر الك زراع البطـاطس لأبعـاد الزر اعـة التعاقديـة

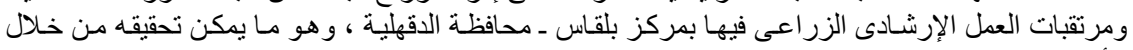

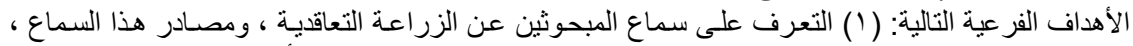

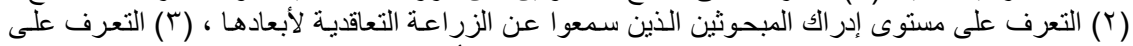

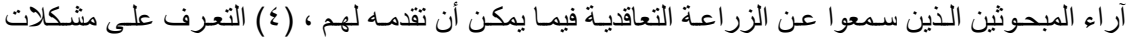

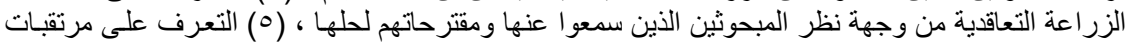

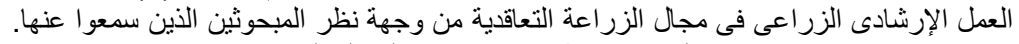

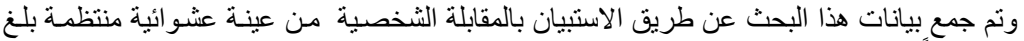

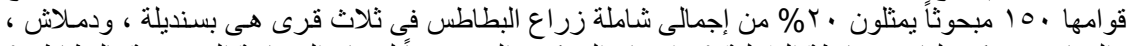

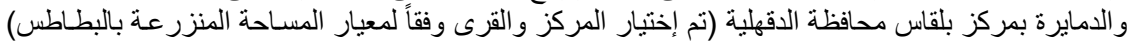

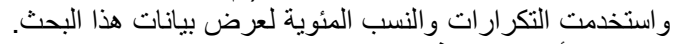
وتلخصت أهم النتائج فيما يلى الثي:

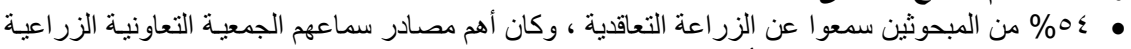

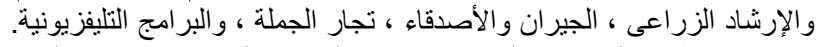

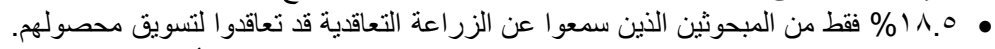

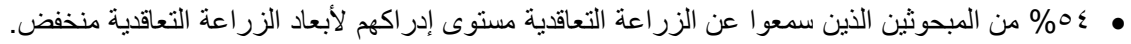

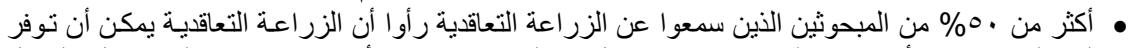

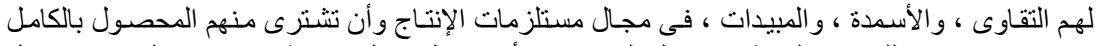

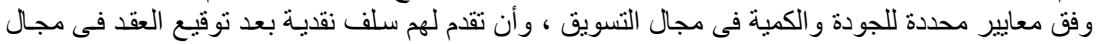
التمويل.

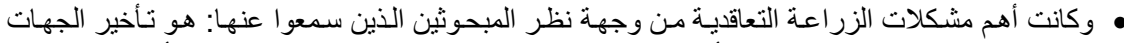

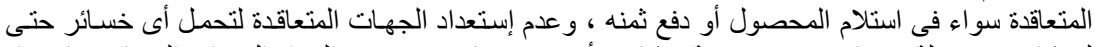

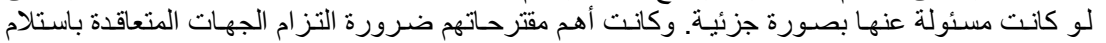

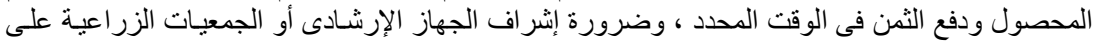
العقد وتتفيذ بنوده.

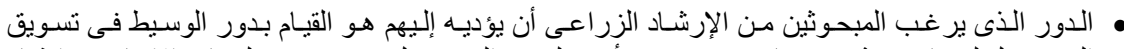

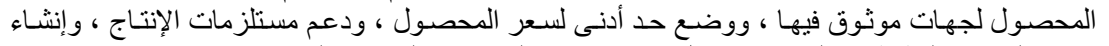

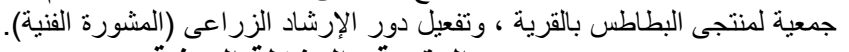
المقدمة والمشكلة البحثية الزية المثية 


\section{Shalaby, Asmaa H.}

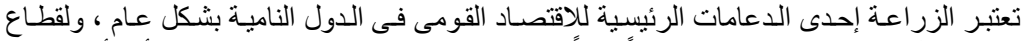

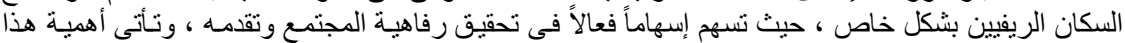

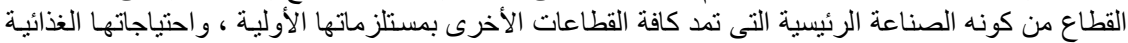

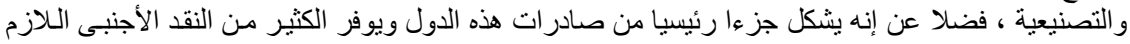

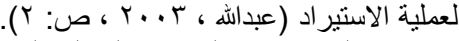

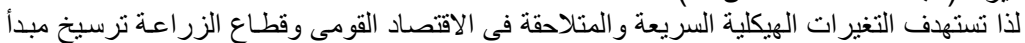

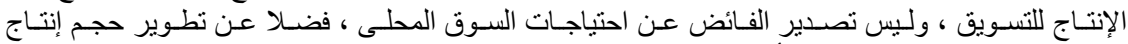

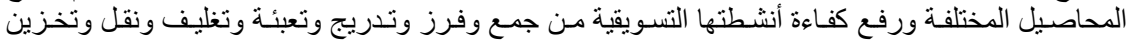

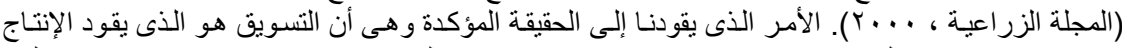

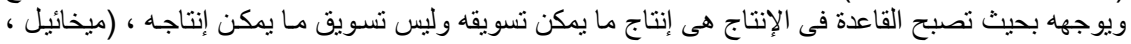

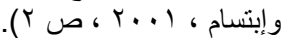

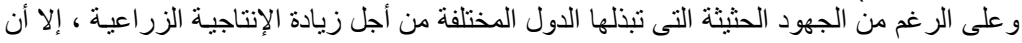

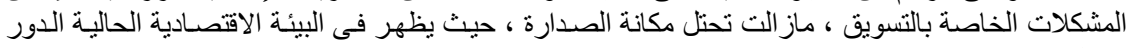

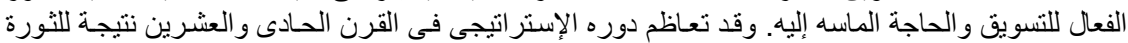

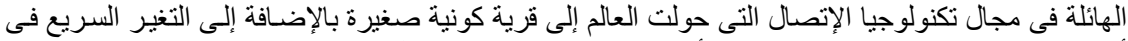

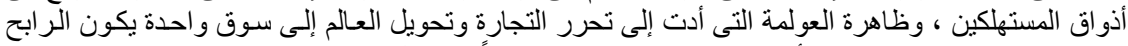

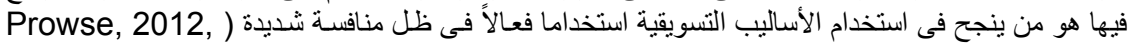

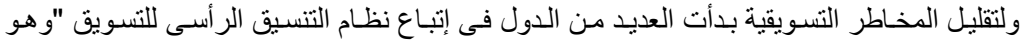

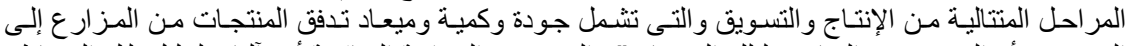

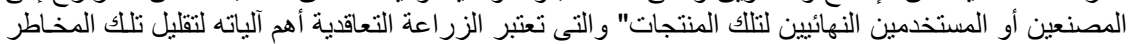

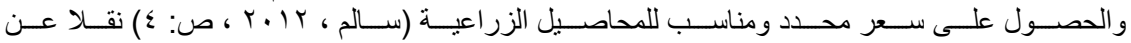

(Secer et al, 2006)

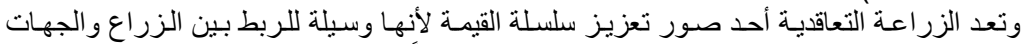

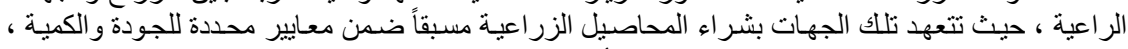

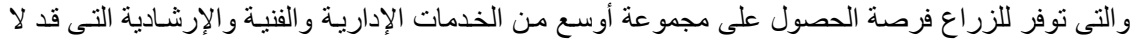

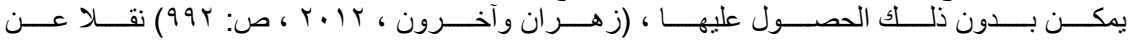
(Hoeffler, 2006, p. 6)

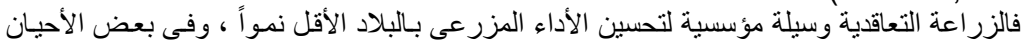

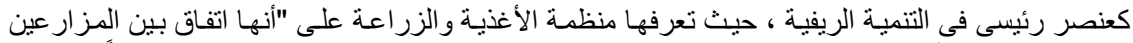

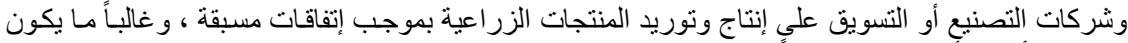

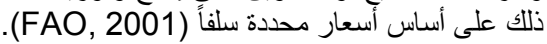

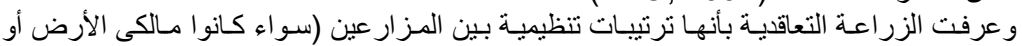

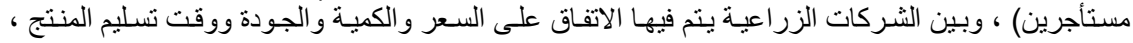
( Singh, 2003, p. 2)

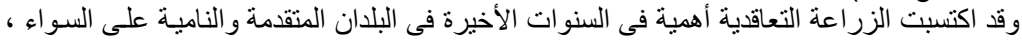

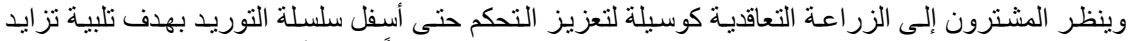

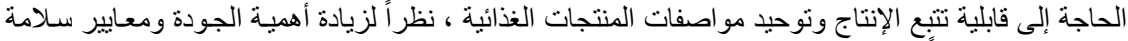

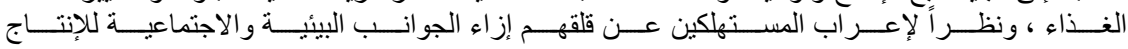

(Rama and Wilkinson, 2008)

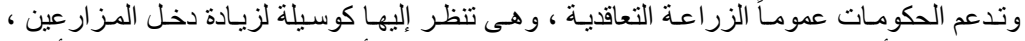

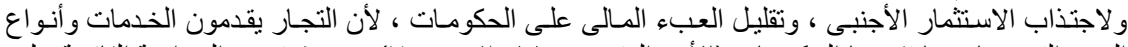

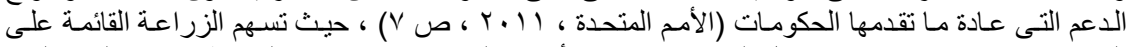

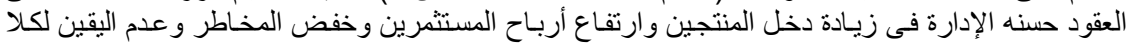

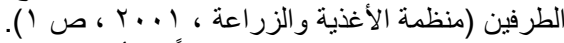

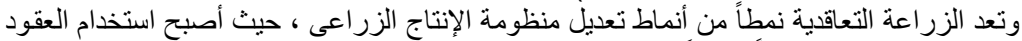

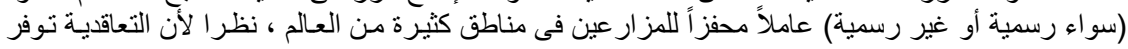




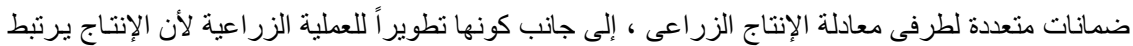

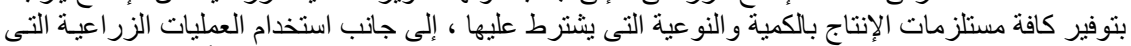

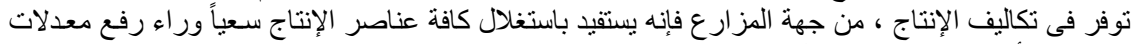

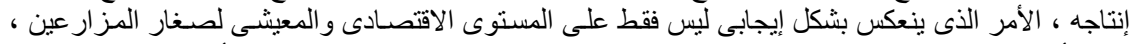

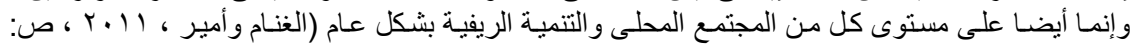

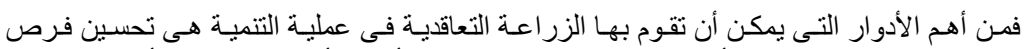

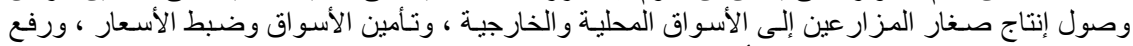

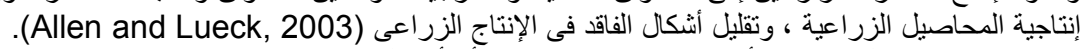

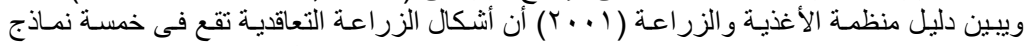

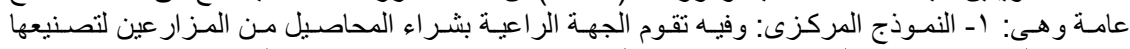

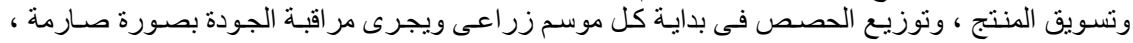

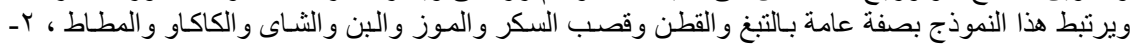

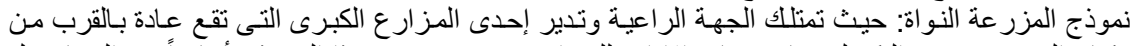

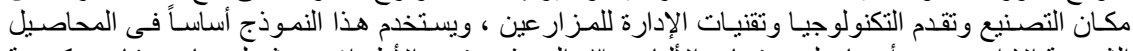

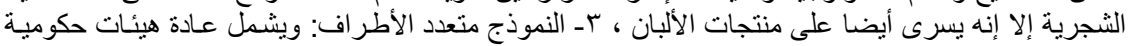

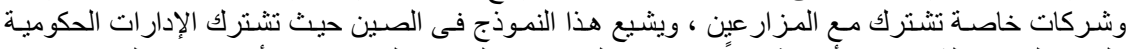

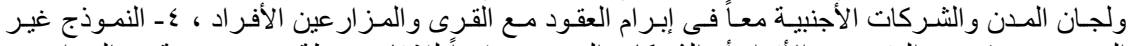

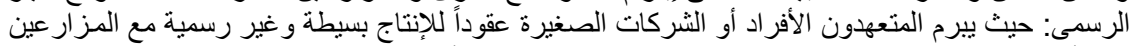

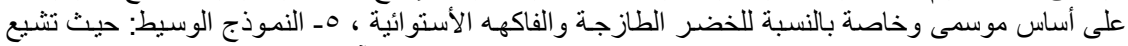

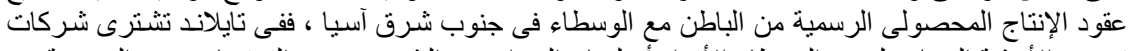

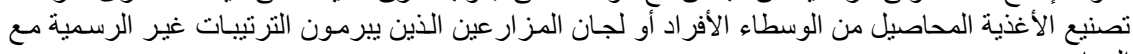

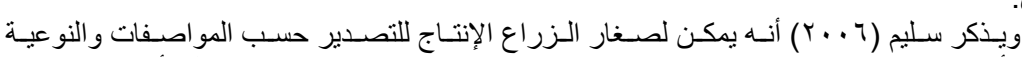

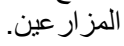

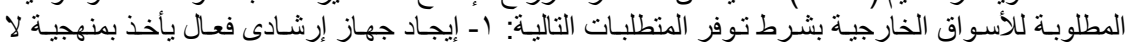

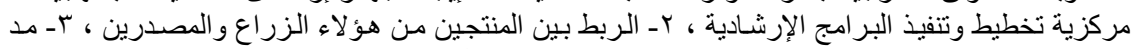

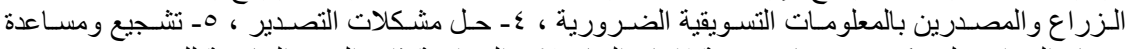

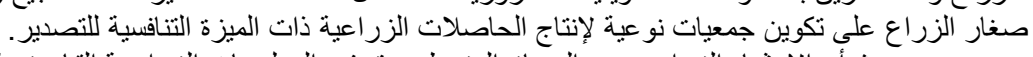

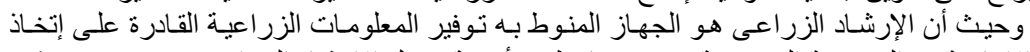

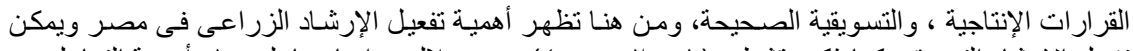

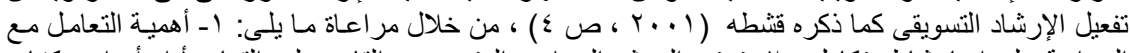

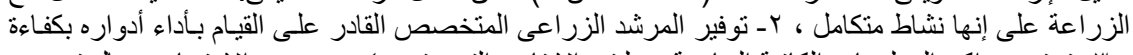

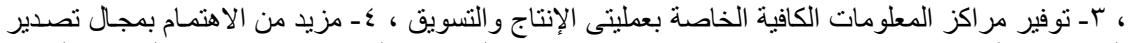

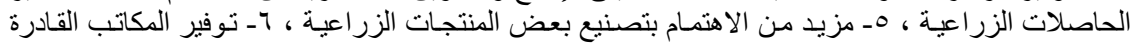

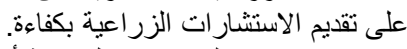

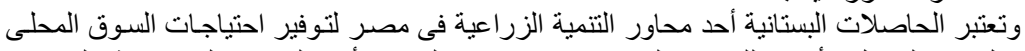

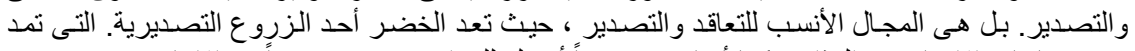

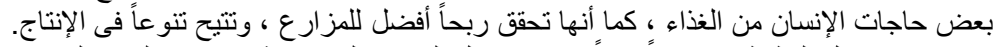

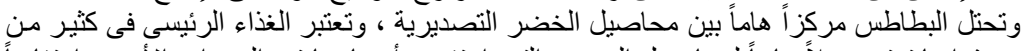

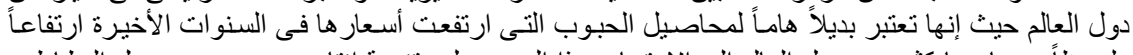

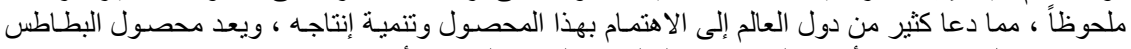

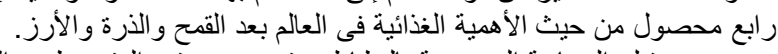

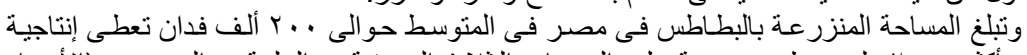

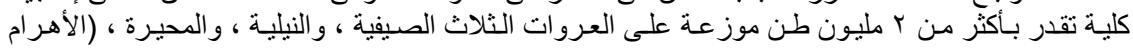

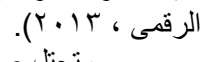

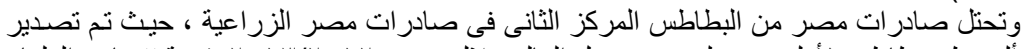

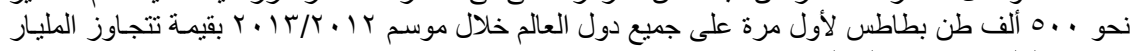

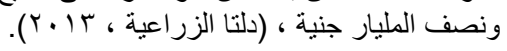


Shalaby, Asmaa H.

ويسأتى سـوق الاتحساد الأوروبـى فى مقدمـة الأسواق المستقبلة للصسادرات المصرية حيث بيستوعب \% \% ب من إجمالى الصنادرات.

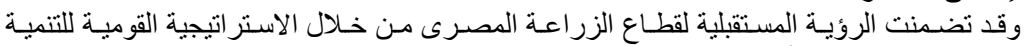

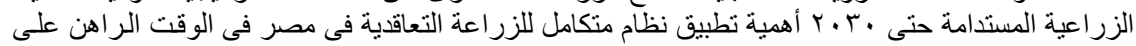

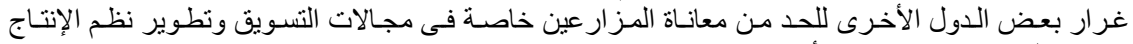

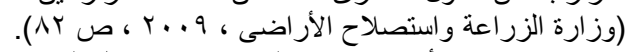

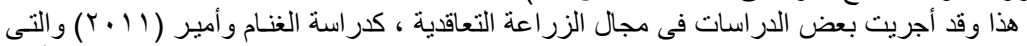

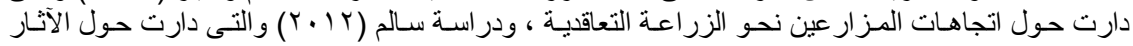

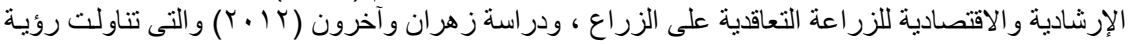

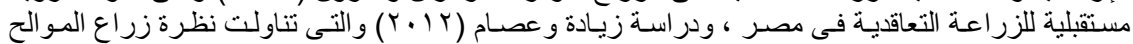

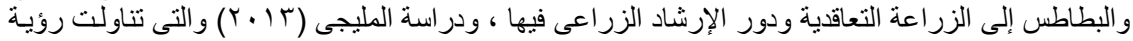

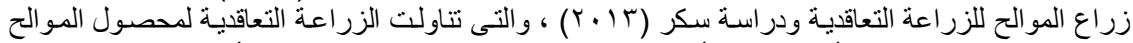

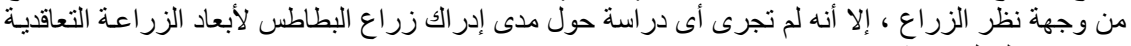
ومرتقبات العمل الإرشادى فيها.

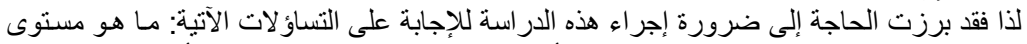

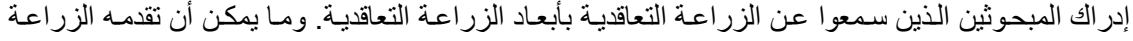

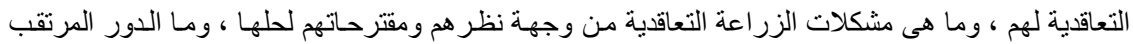

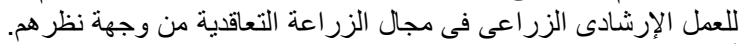

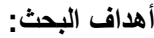

يستهدف هذا البحث بصففة رئيسية التعرف على إدر الك زر اع البطـاطس لأبعـاد الزر اعـة التعاقديـة

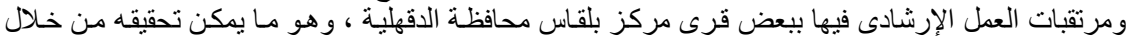

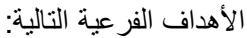

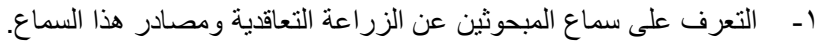

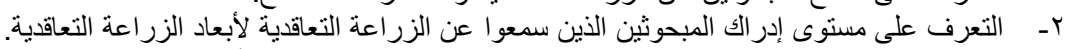

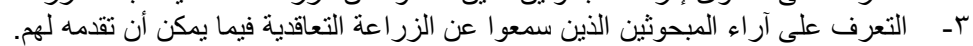

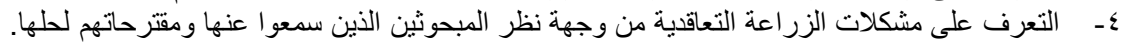

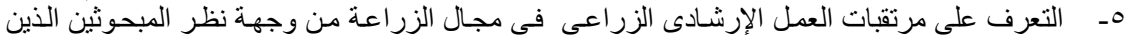
سمعوا عنها.

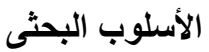

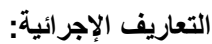

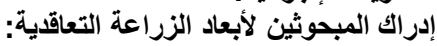

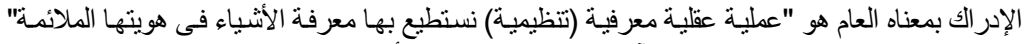

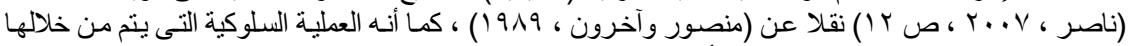

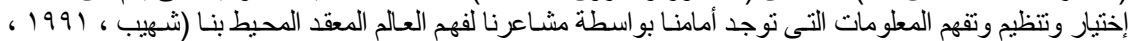

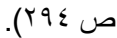

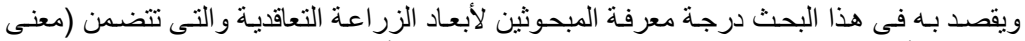

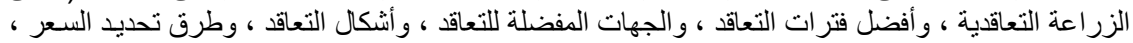

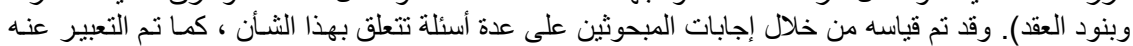
بالدرجات المبات

مرتقبات العمل الإرشادى الزراعى فى مجال الزراعة التعاقدية:

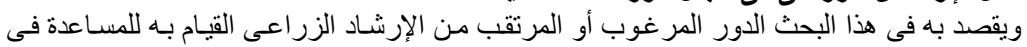

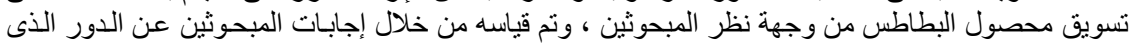

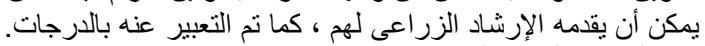
منطقة وشاملة وعينة البحث: الزئة 


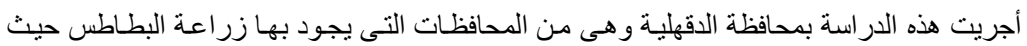

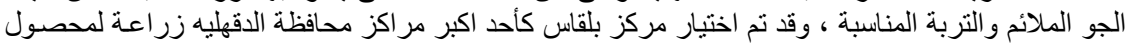

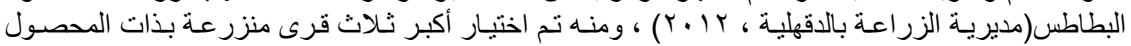

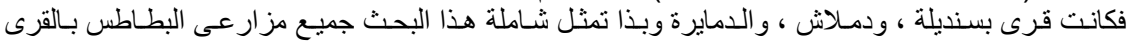

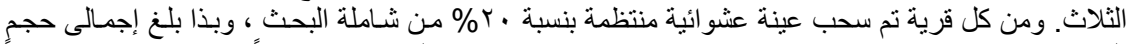

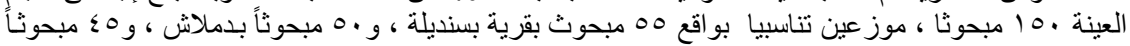

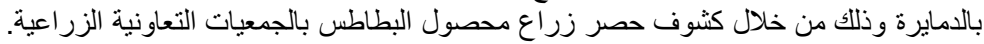

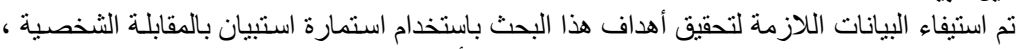

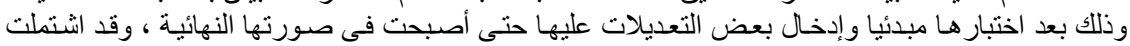

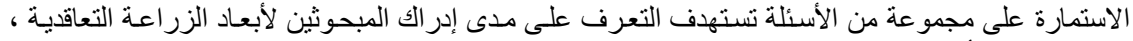

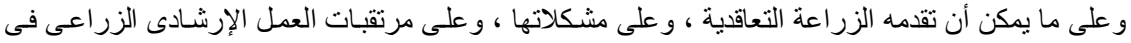

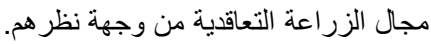

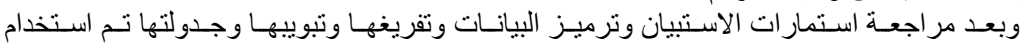

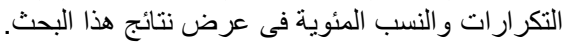

\section{النتائج البحثية}

سماع المبحوثين عن الزراعة التعاقدية ومصادر هذا السماع:

أولا:

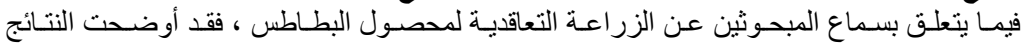

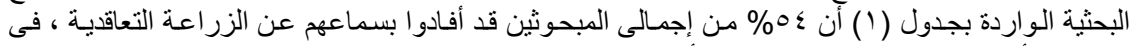

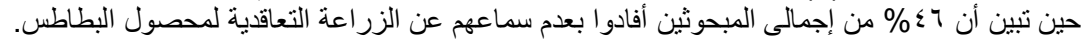

\begin{tabular}{|c|c|c|}
\hline$\%$ & العدد & السماع عن الزراعة التعاقدية \\
\hline $0 \leqslant$ & 11 & مع \\
\hline$\leqslant 7$ & 79 & لم يسمع \\
\hline $1 \ldots$ & 10. & المجمو ع \\
\hline
\end{tabular}

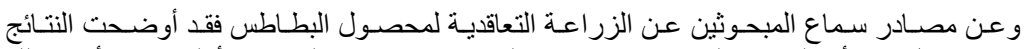

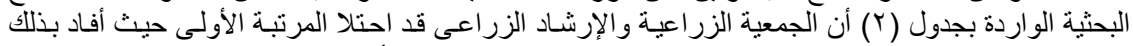

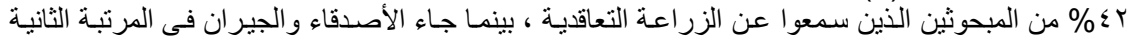

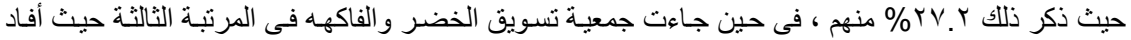

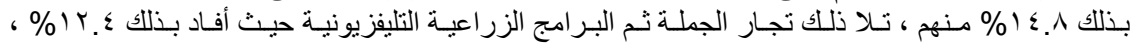

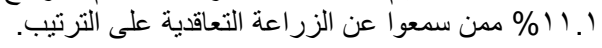




\begin{tabular}{|c|c|c|c|}
\hline$\%$ & التكر ار & مصادر السماع & م \\
\hline$\sum Y_{.} \cdot$ & $r \varepsilon$ & الجمعية الزراعية والإرشاد الزراعى & 1 \\
\hline YV.Y & rt & الأصدقاء و الجيران & $r$ \\
\hline $1 \leq . \wedge$ & IT & جمعية تسويق الخضر و الفاكهه & $r$ \\
\hline IT.z & 1. & تجار الجملة & $\varepsilon$ \\
\hline 11.1 & 9 & |البر امج الزراعية التليفزيونية & 0 \\
\hline
\end{tabular}

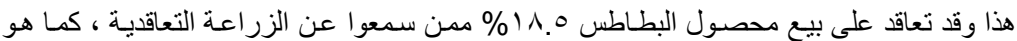

موضح بجدول (r) أما عن جهات التعاقد فكانت جمعية تسويق الخضر ولهن والفاكهه وتجار الجملة. جدول (r) توزيع المبحوثين الذين سمعوا عن الزراعة التعاقدية وفقا لتعاقدهم على بيع المحصول

\begin{tabular}{|c|c|c|}
\hline$\%$ & 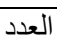 & التعاقد على محصول البطاطس \\
\hline 11.0 & 10 & تعاقد \\
\hline 11.0 & 77 & لم يتعاقد \\
\hline $1 \ldots$ & $\wedge 1$ & | \\
\hline
\end{tabular}

المصدر: جمعت واحتسبت من استمارات الاستبيان

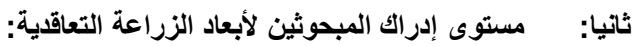

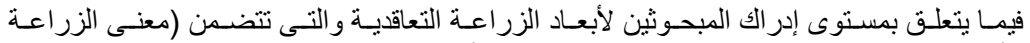

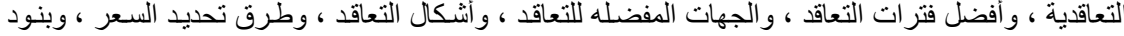

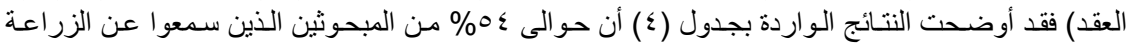

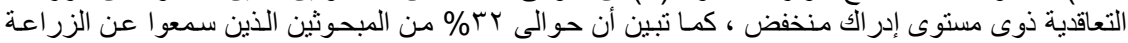

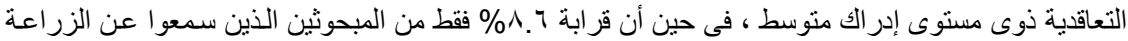

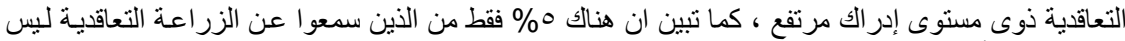
لديهم إدر الك لأبعاد الزرى إعة التعاقدية.

جلول (؛ ) توزيع المبحوثين الذين سمعوا عن الزراعة التعاقدية وفقا لمستوى إدراكهم لأبعاد الزراعة التعاقية

\begin{tabular}{|c|c|c|}
\hline$\%$ & العدد & مستوى الإدر اك \\
\hline 0 & $\varepsilon$ & صفر \\
\hline $0 \leqslant . r$ & $\varepsilon \varepsilon$ & منخفض (1-1) درجة \\
\hline r.I & rT & متوسط (^-ـ (1) درجة \\
\hline$\wedge .7$ & $\mathrm{~V}$ & مرتفع (10 - (Y) درجة \\
\hline $1 \ldots$ & $\wedge 1$ & |المجموع \\
\hline
\end{tabular}

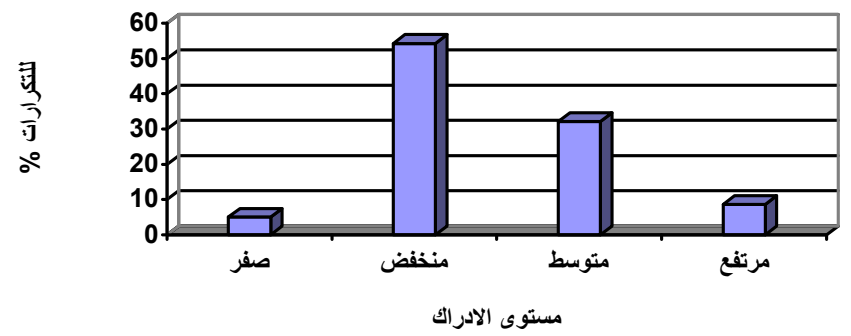

شكل (1) توزيع المبحوثين الذين سمعوا عن الزراعة التعاقية وفقا لمستوى إدراكهم لأبعادها 
وتشير هذه النتيجة إلى الحاجة الملحة إلى بذل المزيد من الجهود الإرشـادية لزيادة إدر الك المبحوثين

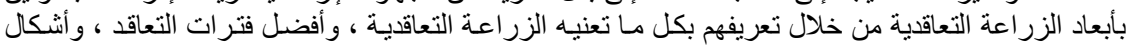

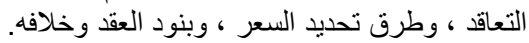

ولمزيد من الإيضـاح سوف نعرض ولند لمدى إدر الك المبحوثين لكل بعد من أبعاد الزر اعـة التعاقديـة على

ا حدة:

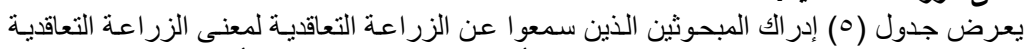

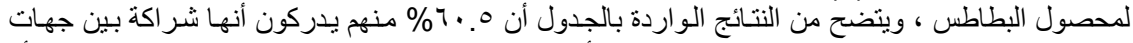

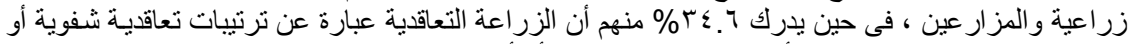

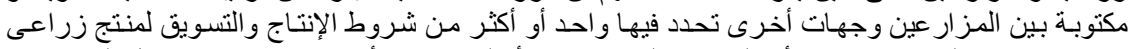

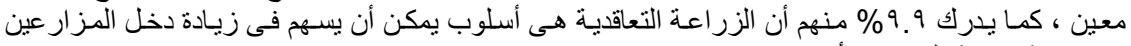
ومضاعفة ربحية الجهات الأخرى.

جدول (0) توزيع المبحوثين الذين سمعوا عن الزراعة التعاقدية وفقا لإدراكهم لمعنى الزراعة التعاقدية

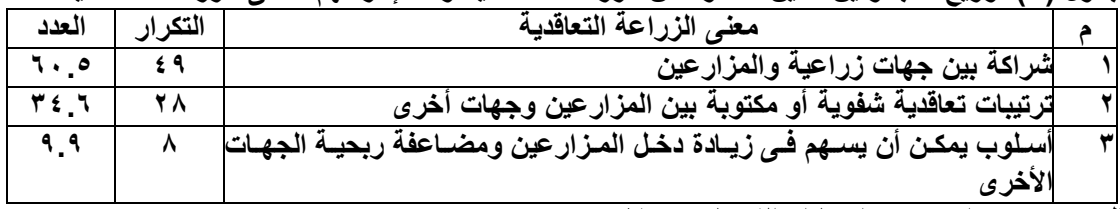

المصدر: جمعت واحتسبت من استمارات الاستبيان ن = الأفرى

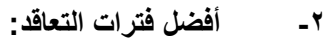

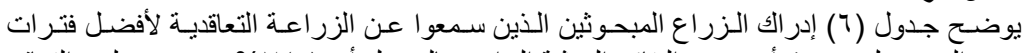

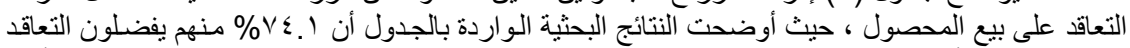

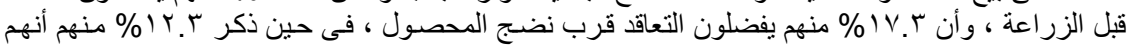

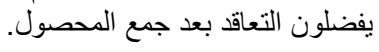
جدول (T) توزيع المبحوثين الذين سمعوا عن الزراعة التعاقدية وفقا لإدراكهم لأفضل فترات التعاقد

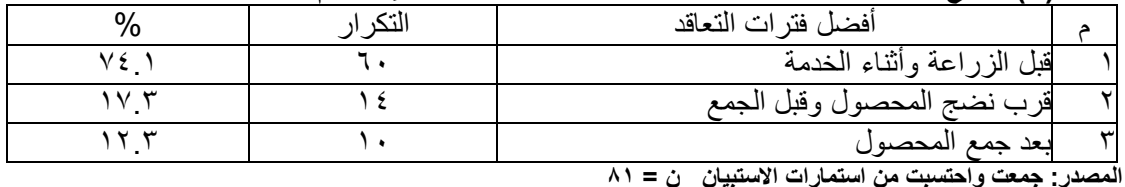

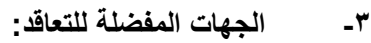

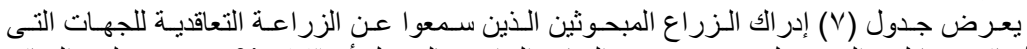

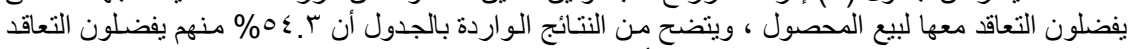

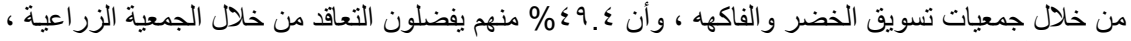

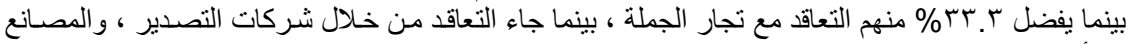
فى أخر تفضيلات المبحوثين بنسب 9.

جدول (V) توزيع المبحوثين الذين سمعوا عن الزراعة التعاقدية وفقا لإدراكه للجهات المفضلة للتعاقد

\begin{tabular}{|c|c|c|c|}
\hline$\%$ & التكر ار & الجهات المفضلة للتعاقد & 5 \\
\hline $0 \leqslant . T$ & $\varepsilon \varepsilon$ & جميعات تسويق الخضر و الفاكهه & 1 \\
\hline$\varepsilon 9 . \varepsilon$ & $\xi$ & |الجمعية الزراعية & $r$ \\
\hline Tr.T & TV & تجار الجملة & $r$ \\
\hline$r \cdot .9$ & ro & شركات التصدير & $\varepsilon$ \\
\hline 11.1 & 9 & |المصانع & 0 \\
\hline
\end{tabular}




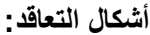

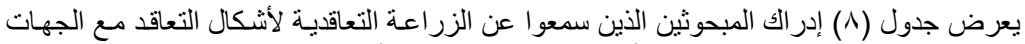

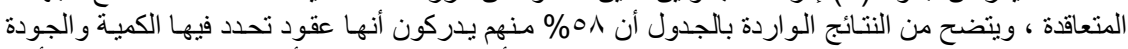

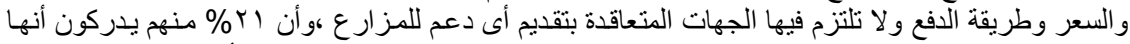

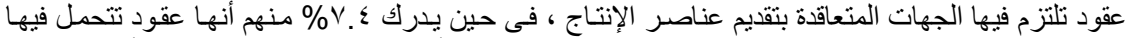

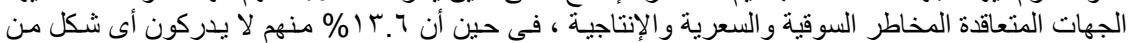

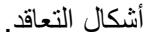

جدول (^) توزيع المبحوثين الذين سمعوا عن الزراعة التعاقدية وفقا لإدراكهم لأشكال التعاقد

\begin{tabular}{|c|c|c|c|}
\hline$\%$ & 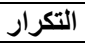 & أشكال التعاقد & b \\
\hline$\bullet \wedge . \cdot$ & $\varepsilon V$ & عقود تحدد فيها الكمية والجودة والسعر وطريقة الدفع & 1 \\
\hline ri.• & IV & عقود تلتزم فيها الجهات المتعاقدة بتقدم عناصر الإنتاج & $r$ \\
\hline $\mathrm{V. \varepsilon}$ & 7 & عقود تتحمل فيها الجهات المتعاقدة المخاطر السوقية والسعرية والإتتاجية & $r$ \\
\hline $1 \% .7$ & 11 & ل الا يعرف & $\varepsilon$ \\
\hline
\end{tabular}

هـ

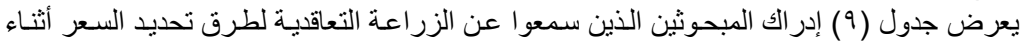

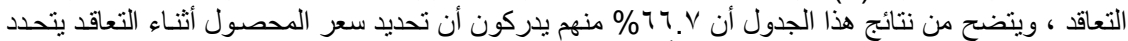

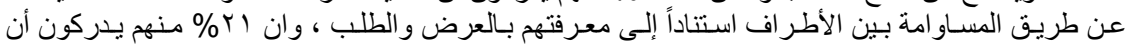

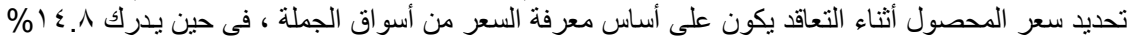

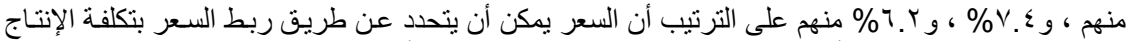

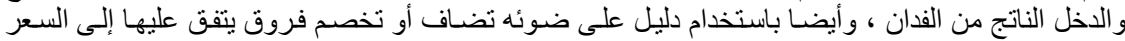

الموجود أو السائد فى سوق معين ، وكذا من خلان لجن لجنة فنية أو هيئة.

جدول (9) توزيع المبحوثين الذين سمعوا عن الزراعة التعاقدية لطرق تحديد السعر أثناء التعاقد

\begin{tabular}{|c|c|c|c|}
\hline$\%$ & 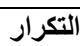 & طرق تحديد السعر & م \\
\hline 79.1 & $0 \leqslant$ & المساوامة بين الأطراف استناداً إلى معرفتهم بالعرض والطلب & 1 \\
\hline ri." & IV & عن طريق معرفة السعر من أسواق الجملة & $r$ \\
\hline $1 \leqslant . \wedge$ & Ir & عن طريق ربط السعر بتكلفة الإنتاج والاخل الناتج من الفدان & $r$ \\
\hline$V . \xi$ & 7 & الموجتود أو السيل على في ضوئه تضاف أو تخصم فروق يتفق عليها إلى السـر & $\xi$ \\
\hline 7. 1 & 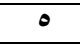 & من خلال لجنة فنية أو هيئة & 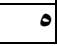 \\
\hline
\end{tabular}

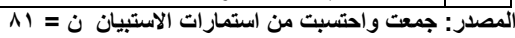

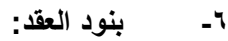

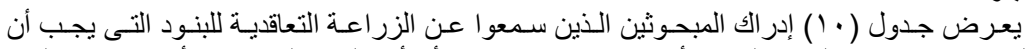

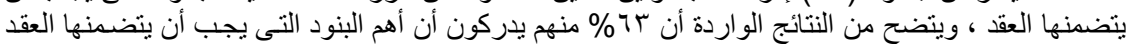

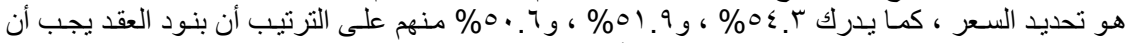

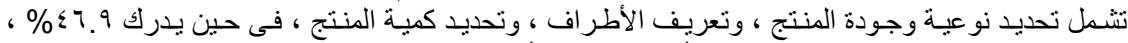

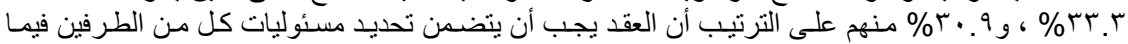

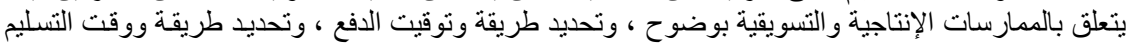

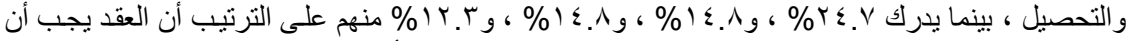

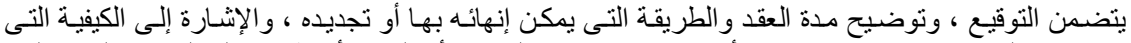

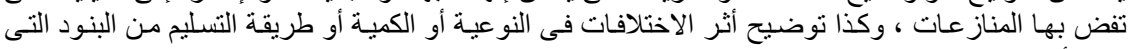
يجب أن يتضمنها العقد. 
جدول ( • 1) توزيع المبحوثين الذين سمعوا عن الزراعة التعاقية وفقا لإدراكهم لبنود العقد

\begin{tabular}{|c|c|c|c|}
\hline$\%$ & التكرار & بنود العقد & 5 \\
\hline 7r.. & 01 & تحديد السعر & 1 \\
\hline $0 \leqslant . r$ & $\leqslant \leqslant$ & تحديد نوعية وجودة المنتج & r \\
\hline 01.9 & $\varepsilon r$ & تُعريف الأطر اف & $r$ \\
\hline $0 . .7$ & $\leqslant 1$ & تحديد كمية المنتج & $\varepsilon$ \\
\hline$\$ 4.9$ & $r \wedge$ & تحديد مسئوليات كل طرف & 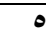 \\
\hline rr.r & $r V$ & تحديد طريقة وتوقيت الدفع & 7 \\
\hline$r \cdot .9$ & ro & تحديد طريقة ووقت التسليم والتحصيل & $\mathrm{V}$ \\
\hline$r \leqslant . V$ & r. & |التوقيع & $\Lambda$ \\
\hline $1 \leqslant . \wedge$ & Ir & تحديد مدة العقد وكيفية إنهائه & 9 \\
\hline $1 \leqslant . \wedge$ & Ir & كيفية فض المنازعات & 1. \\
\hline IY.r & 1. & توضيح أثر الاختلافات فى النوعية أو الكمية أو طريقة التسليم & 11 \\
\hline
\end{tabular}

ثالثا: آراء المبحوثين الذين سمعوا عن الزراعة التعاقدية فيما يمكن أن تقدمه الجهات المتعاقدة:

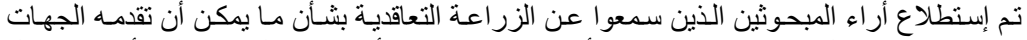

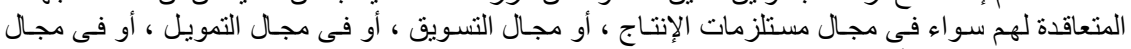

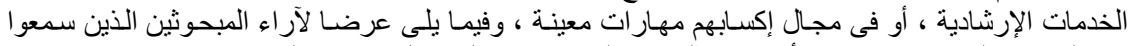

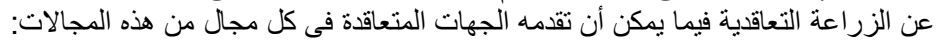

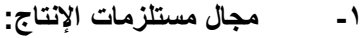

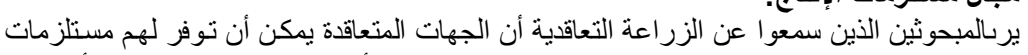

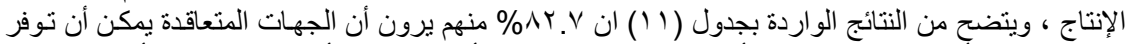

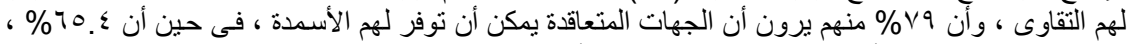

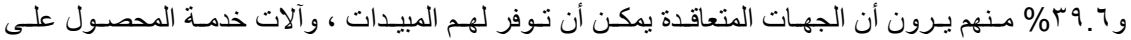

جدول (1 1 ) توزيع المبحوثين الذين سمعوا عن الزراعة التعاقديـة وفقـا لرأيهم فيمـا يمكن أن تقدمه الجهات

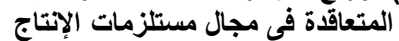

\begin{tabular}{|c|c|c|c|}
\hline$\%$ & التكرار & ما يمكن أن تقدمه الجهات المتعاقدة في مجال مستلزمات الإنتاج & a \\
\hline Ar.v & TV & توفير التقاوى & 1 \\
\hline V9. & $7 \varepsilon$ & توفير الأسمدة & 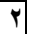 \\
\hline 70.5 & or & توفير المبيدات & $\varphi$ \\
\hline r9.7 & rr & توفير آلات خدمة المحصول & $\xi$ \\
\hline
\end{tabular}

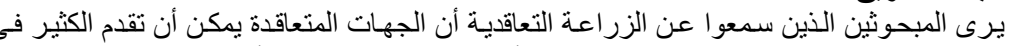

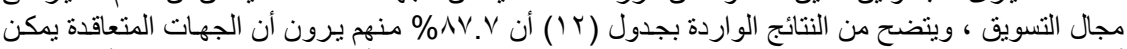

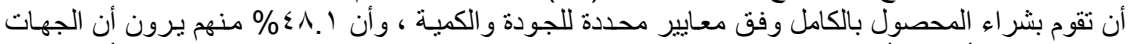

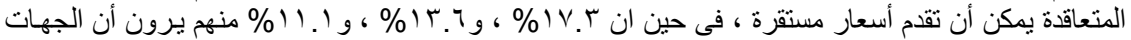

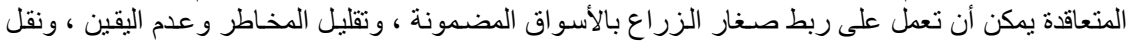
المحصول على الترتيب.

جدول (r ا ) توزيع المبحوثين الذين سمعوا عن الزراعة التعاقديـة وفقـا لر أيهم فيمـا يمكن أن تقدمه الجهات

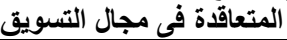

\begin{tabular}{|c|c|c|}
\hline$\%$ & 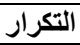 & م مـا يمكن أن تقدمه الجهات المتعاقدة فى مجال التسويق \\
\hline$\Lambda \vee . V$ & VI & ثر اء المحصول بالكامل وفق معايير محددة للجودة والكمية \\
\hline
\end{tabular}


Shalaby, Asmaa H.

\begin{tabular}{|c|c|c|c|}
\hline$\varepsilon \wedge .1$ & rq & تقليم أسعار مستقرة & $r$ \\
\hline IV.r & $1 \leq$ & ربط صغار الزراع بالأسواق المضمونة & $r$ \\
\hline $1 \% .7$ & 11 & تقليل المخاطر وعدم اليقين & $\varepsilon$ \\
\hline 11.1 & 9 & نقل المحصول & 0 \\
\hline
\end{tabular}

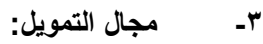

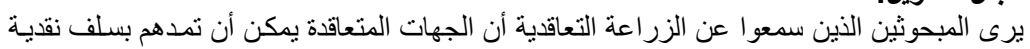

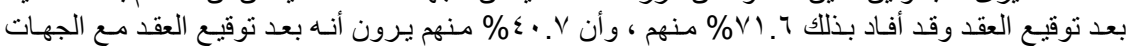

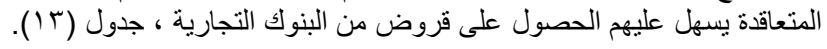

جدول (ب ا ) توزيع المبحوثين الذين سمعوا عن الزراعة التعاقديـة وفقـا لر أيهم فيمـا يمكن أن تقدمه الجهات

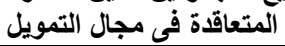

\begin{tabular}{|c|c|c|}
\hline$\%$ & 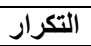 & ما يمكن أن تقدمه الجهات المتعاقدة في مجال التمويل \\
\hline$\sqrt{41.7}$ & $\Delta \wedge$ & تقديم سلف نقدية بعد توقيع العقد \\
\hline$\varepsilon \cdot . V$ & $r r$ & تسهيل الحصول على قروض من البنوك التجارية بموجب العقد \\
\hline
\end{tabular}

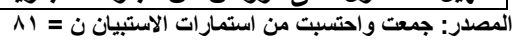

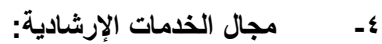

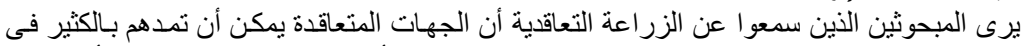

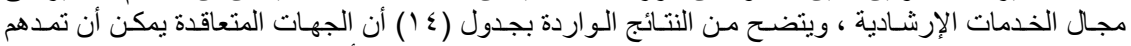

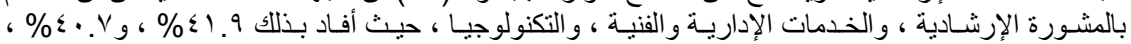

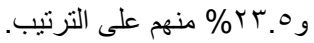

جدول ( ؛ ا) توزيع المبحوثين الذين سمعوا عن الزراعة التعاقدية وفقا لر أيهم فيمـا يمكن أن تقدمـه الجهات

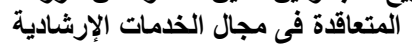

\begin{tabular}{|c|c|c|c|}
\hline$\%$ & 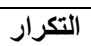 & ما يمكن أن تقدمه الجهات المتعاقدة فى مجال الخدمات الإرشادية & م \\
\hline$\$ 1.9$ & $r \varepsilon$ & |المشورة الإرشادية & 1 \\
\hline$\varepsilon \cdot . V$ & $r r$ & | الخذمات الإدارية والفنية & $r$ \\
\hline rr.o & 19 & | التكنولوجيا & $r$ \\
\hline
\end{tabular}

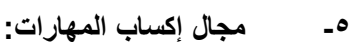

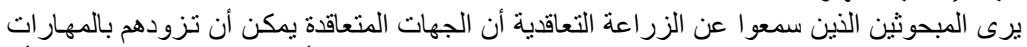

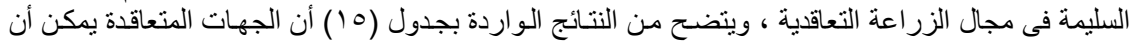

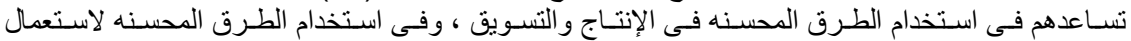

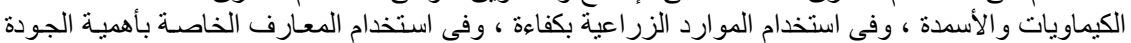

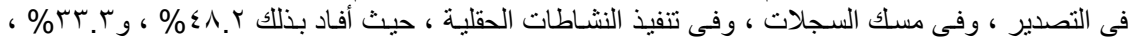

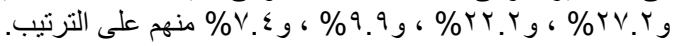

جدول (0 1 ) توزيع المبحوثين الذين سمعوا عن الزراعة التعاقديـة وفقـا لر أيهم فيمـا يمكن أن تقدمـه الجهات

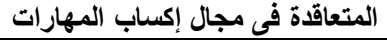

\begin{tabular}{|c|c|c|c|}
\hline$\%$ & 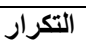 & ما يمكن أن تقدمه الجهات المتعاقدة فى مجال إكساب المهارات & م \\
\hline$\varepsilon \wedge . Y$ & $r q$ & |استخدام الطرق المحسنه فى الإنتاج والتسويق & 1 \\
\hline rr.r & rV & استخدام الطرق المحسنه فى استعمـال الكيماويات والمبيدات & $r$ \\
\hline TV.T & rY & استخدام الموارد الزراعية بكفاءة & $\mathrm{T}$ \\
\hline
\end{tabular}




\begin{tabular}{|c|c|c|c|}
\hline YY.Y & 11 & |ستخدام المعارف الخاصة بأهمية الجودة في التصدير & $\varepsilon$ \\
\hline 9.9 & $\Lambda$ & مسك السجلات & 0 \\
\hline V.\& & 9 & الحصول على خبرات في مجال تنفيذ النشاطات الحقلية & 7 \\
\hline
\end{tabular}

رابعا: مشـكلات الزراعة التعاقديـة مـن وجهة نظر المبحوثين الذين سـمعوا عنها ومقترحستهم للتظلب عليها:

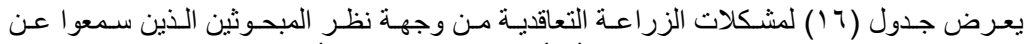

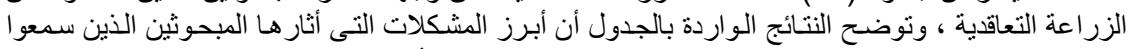

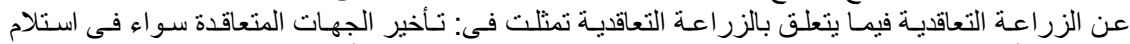

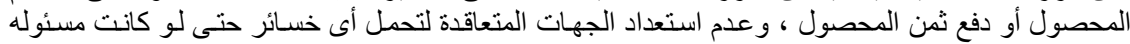

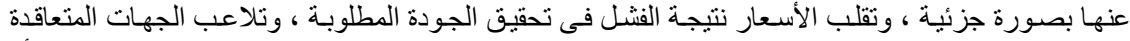

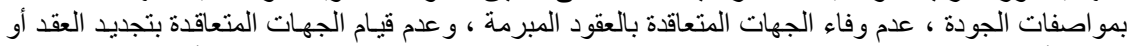

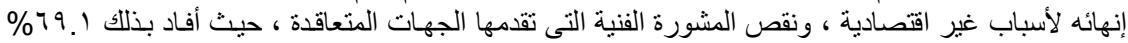

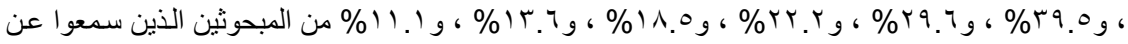

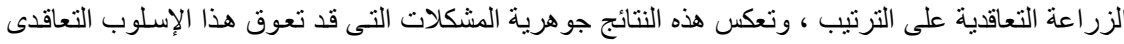

$$
\text { الذى يهدف إلى خدمة الزراع. }
$$

جدول (7 1 ) توزيع المبحوثين الذين سمعوا عن الزراعة التعاقدية وفقا لذكرهم مشكلات الزراعة التعاقدية

\begin{tabular}{|c|c|c|c|}
\hline$\%$ & 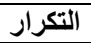 & المشكلات & b \\
\hline 79.1 & 07 & 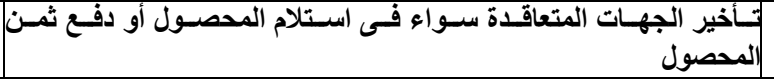 & 1 \\
\hline$r 9.0$ & $r r$ & عنها بصورة جزئية استعداد الجنعاقدة لتحمل أى خسـائر حتى لو كاتت مسئولها & $r$ \\
\hline r9.7 & $r \varepsilon$ & تقلب الأسعار نتيجة الفشل فى تحقيق الجودة المطلوبة & $r$ \\
\hline Yr.r & 11 & تلاعب الجهات المتعاقدة بمواصفات الجودة & $\varepsilon$ \\
\hline 11.0 & 10 & عدم وفاء الجهات المتعاقدة بالعقود المبرمة & $\bullet$ \\
\hline $1 \% .7$ & 11 & عدم قيام الجهات المتعاقدة بتجديد العقد أو إنهائه لأسباب غير اقتصادية & 7 \\
\hline 11.1 & 9 & |قصص المشورة الفنية التى تقدمها الجهات المتعاقدة & $\mathrm{v}$ \\
\hline
\end{tabular}

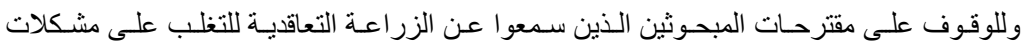

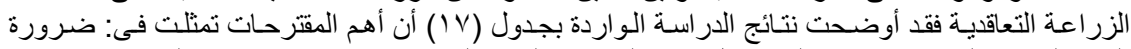

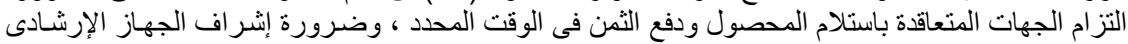

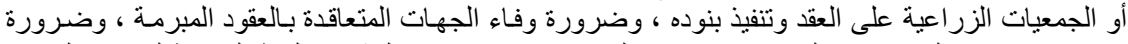

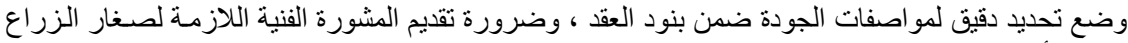

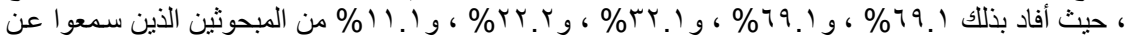
الزراعة التعاقدية على الترتيب.

جدول (IV) توزيع المبحوثين الذين سمعوا عن الزراعة التعاقدية وفقا لمقترحاتهم للتظلب على مشكلات الزراعة التعاقدية

\begin{tabular}{|c|c|c|c|}
\hline$\%$ & 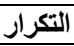 & المقترحات & \\
\hline 79.1 & 07 & ضرورة التزام الجهات المتعاقدة باستلام المحصول ودفع الثمن فى الوقت المحدد & 1 \\
\hline 79.1 & 07 & ضرورة إشراف الجهاز الإرشادى أو الجمعيات الزراعية على العقد وتتفيذ بنوده & $Y$ \\
\hline rY. & rq & ضرورة وفاء الجهات المتعاقدة بالعقود المبرمة & 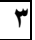 \\
\hline YY. & 11 & ضرورة وضع تحليد دقيق لمواصفات الجودة ضمن بنود العقد & $\varepsilon$ \\
\hline 11.1 & 9 & ضرورة تقديم المشورة الفنية اللازمة لصغار الزراع & 0 \\
\hline
\end{tabular}


خامسا: مرتقبات العمل الإرشادى الزراعى فى مجال الزراعة التعاقية:

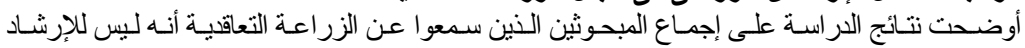

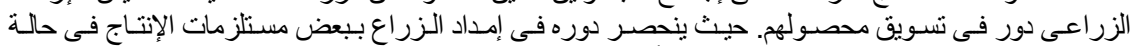
تو افرها بمخازن الجمعية التعاونية الزر اعية و أيضاً إمدادهم ببعض الإرشادات الفنية التىى قد تسـاعد في زيادة الإنتاجية

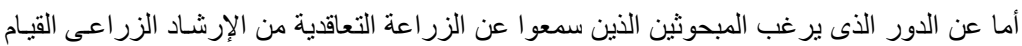

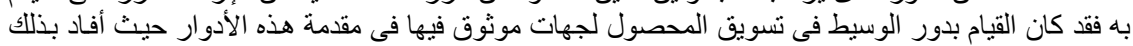

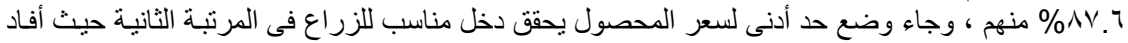

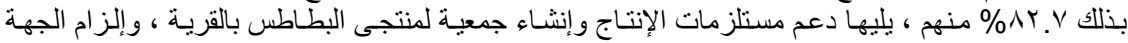

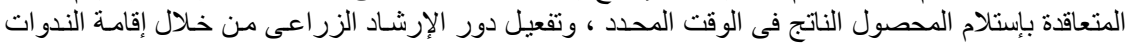

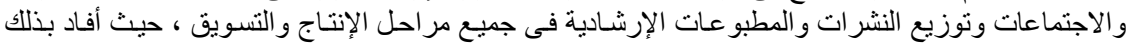

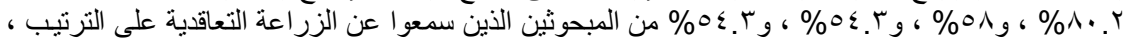

جدول (1) ( ) (1).

جدول (1 ا ) توزيع المبحوثين الذين سـمعوا عن الزراعـة التعاقديـة وفقا للـدور المرغوب (المرتقب) مـن

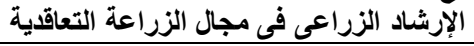

\begin{tabular}{|c|c|c|c|}
\hline$\%$ & التكرار & الدور المرغوب (المرتقب) من الإرشاد الزراعى & p \\
\hline$\wedge \vee .7$ & VI & |القيام بدور الوسيط فى تسويق المحصول لجهات موثوق فيها & 1 \\
\hline$\wedge r . V$ & TV & وضع حد أدنى لسعر المحصول يحقق دخل مناسب للزراع & Y \\
\hline$\Lambda \cdot . r$ & 70 & |دعم مستلزمات الإتتاج & $r$ \\
\hline $0 \Lambda_{.}$. & $\varepsilon V$ & |إنشاء جمعية لمنتجى البطاطس بالقرية & $\varepsilon$ \\
\hline $0 \leqslant . r$ & $\leqslant 1$ & إلزلزام الجهة المتعاقدة باستلام المحصول الناتج فى الوقت المحدد & ○ \\
\hline $0 \leqslant . \Gamma$ & $\leqslant 1$ & 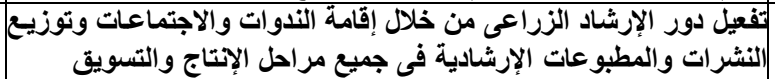 & 7 \\
\hline
\end{tabular}

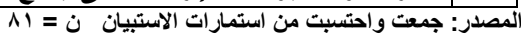

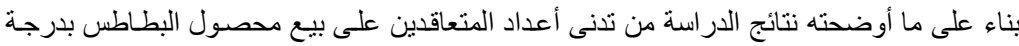

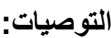

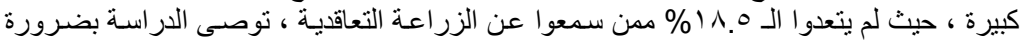

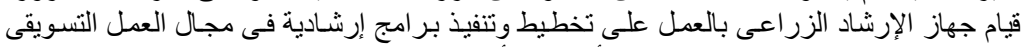

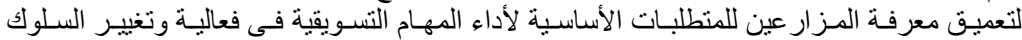

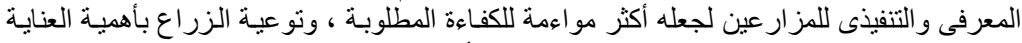

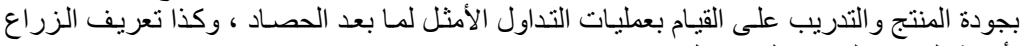
بأهمية التعاقد على بيع النّورئ المحصول.

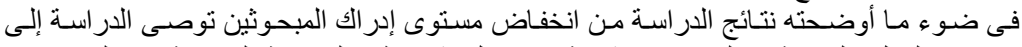

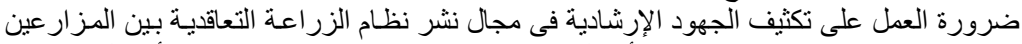

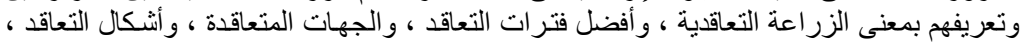

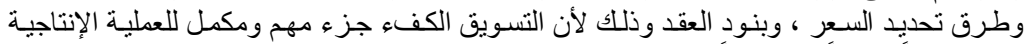

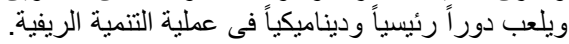

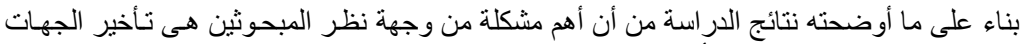

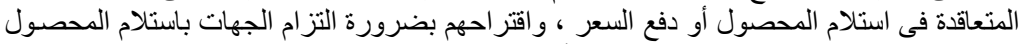

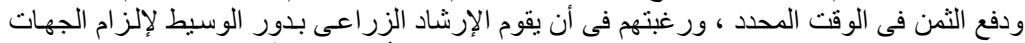

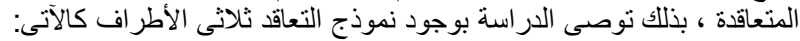

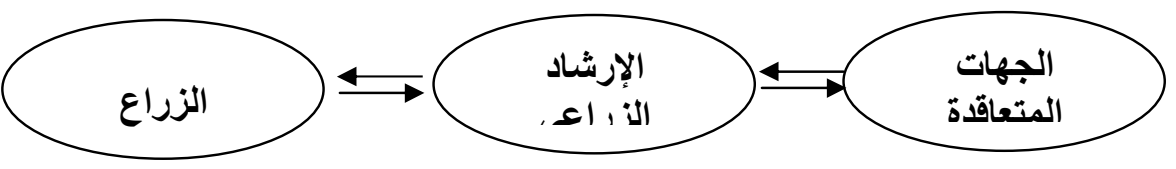




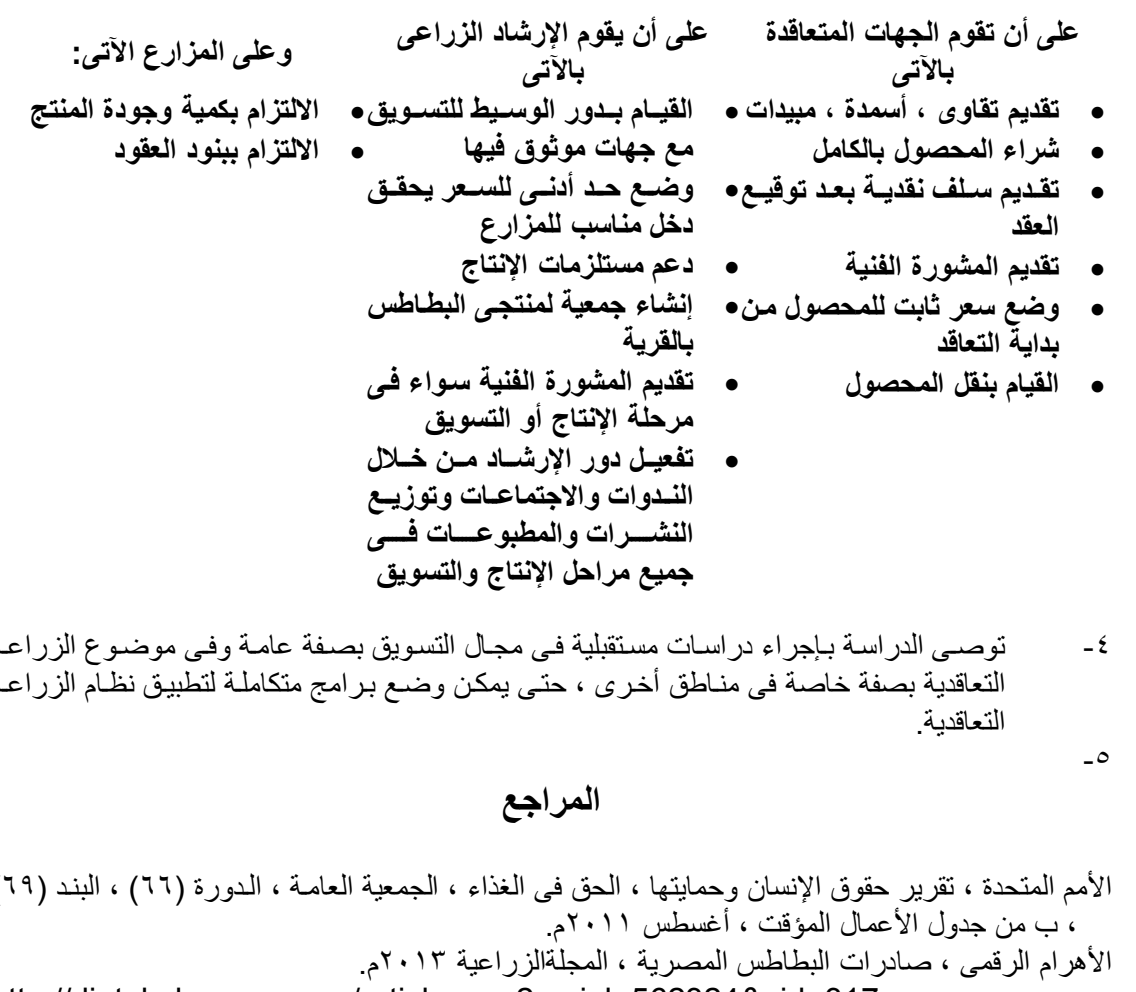

http://digtal.ahram.org.eg/articleaspx2serial=562324\&eid=317

date of visit 2/6/2013

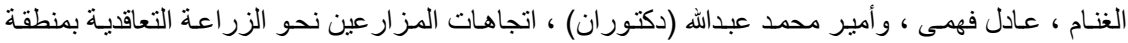

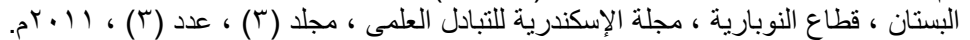

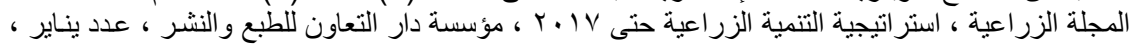

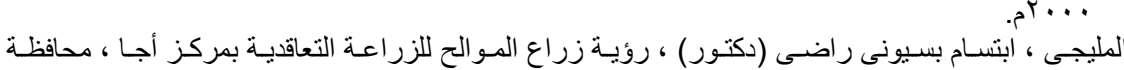

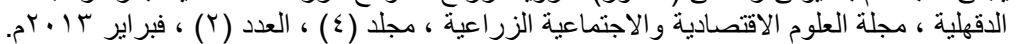

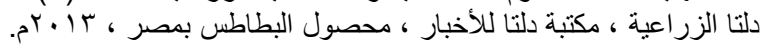
www.deltaagro.com/lang/ar/deltalibrarydetails/35 date of visit $7 / 5 / 2013$

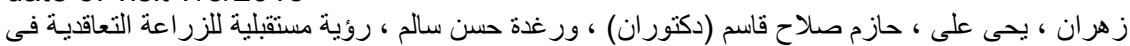

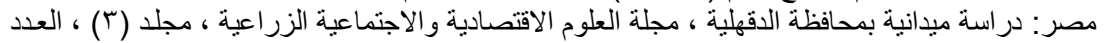

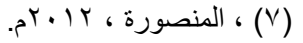

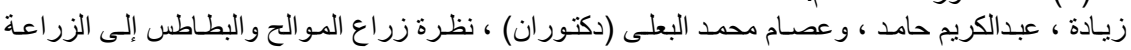

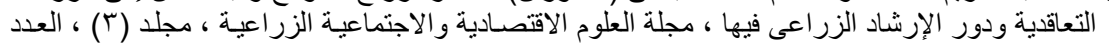

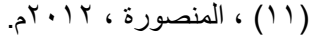




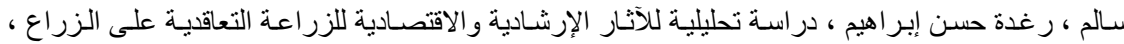

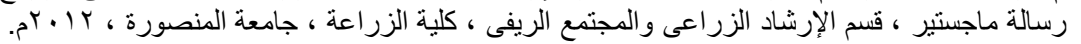

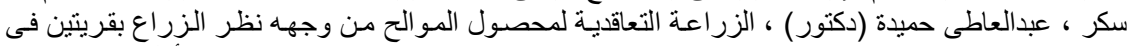

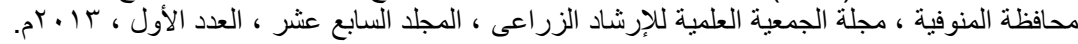

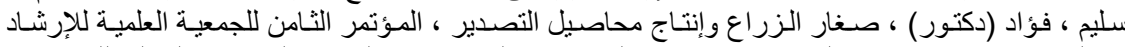

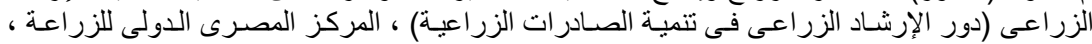

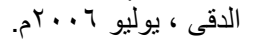

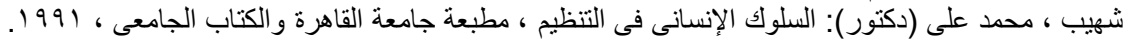

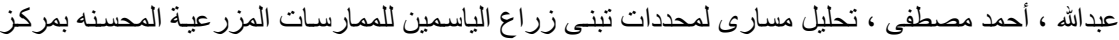

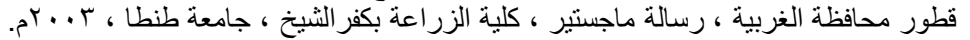

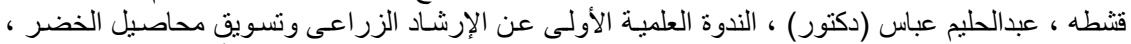

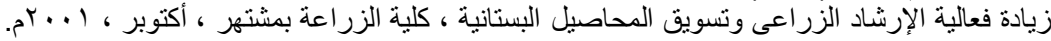

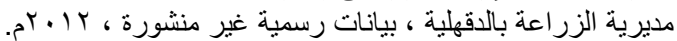

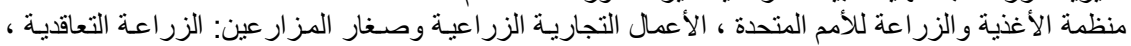

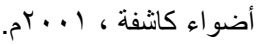

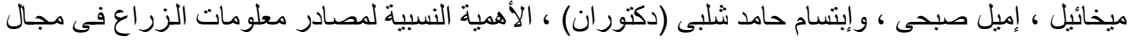

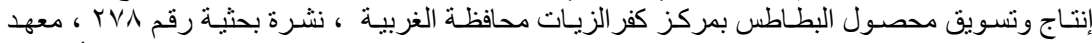

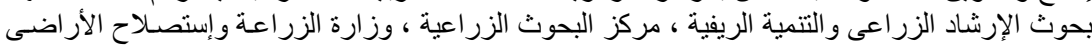

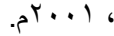

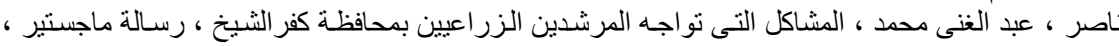

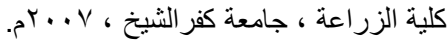

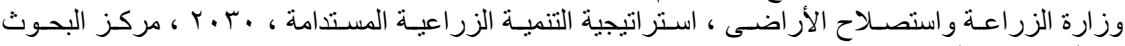

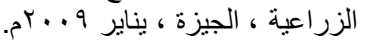

Allen, Dw and Lueck, D. (2003): The nature of the Farm: contracts, risk and organization agriculture. The Mit press: Cambridge.

FAO (2001): Contract Farming: Partner Ships for Growth, Agricultural Services Bulletin.

Prowse, M. (2012): Contract Farning in Developing countries: A review, Agence Francaise Development (AFD), France.

Rama R. and J. Wilkinson (2008): "Foreign direct investment and agri-food value chains in developing countries. A review of the main issues. Commodity Market Review 2007-2008 (FAO, Rome).

Singh, s. (2003): Contract Farming in India: Impacts on Women and Child Workers, International Institute for Environment and Development, Gujarat, India. (on-Line):

Available at: http://www.pubs.iied.org/pdfs/928IIIED.pdf.

\section{POTATO FARMERS PERCEPTION TO DIMENSIONS OF CONTRACT FARMING AND PROSPECTS OF AGRICULTURAL EXTENSION WORK THEREIN IN SOME VILLAGES, BELKAS DISTRICT, DAKAHLIA GOVERNORATE Shalaby, Asmaa H.}

Agricultural Extension \& Rural Development Research Institute, ARC

\section{ABSTRACT}


The main objective of this research was to study potato farmers perception to dimensions of contract farming and prospects of agricultural extension work therein some villages, Belkas district, Dakahlia governorate. The specific objective were stated as follows: 1- To identify the respondents hearing. 2- To identify the respondents perception level to dimensions of control farming. 3- To identify the opinions of respondents about contract farming, 4- To identify the problems of contract farming from the view point of respondents, and their suggestions. 5- To identify the prospects of agricultural extension work about contract farming.

A well prepared and pre-tested questionnaire was used to collect data for this research through interviewing 150 respondents in three villages, Belkas district, Dakhlia governorate. Frequencies, percentage were used for analyzing data statistically.

The most important results are as follows:

- $54 \%$ of respondents heard about contract farming, and the most important sources of their hearing was: agricultural cooperative and agricultural extension, and neighbors, marketing organization and TV programs.

- $10 \%$ only of respondents was contracted to marketing their products.

- $54 \%$ of respondents had low level of perception to dimensions of contract farming.

- More than $50 \%$ of respondents prefer to contract as follows: sponsors will provide them with seeds, chemical fertilizers, pesticides, delivering the production.

- The main problems of contract farming from view point of respondents were delaying in crop transport, and paying the price, and the main suggestions were delivering the crop, paying the price of it and agricultural extension will play a facilitator in contract.

- Prospects of agricultural extension work about contract farming were: agricultural extension will play as a facilitator role in contract farming, determining preliminary price at the beginning of contract, helpful aid to inputs, establishment vegetable marketing association in the village and to make the agricultural extension role more activity.

$$
\text { كلية الزية الزراعة - جامعة المنصورة - جامعة كفر الشيخ }
$$

